\title{
Optimum Shape And Location Of Opening In Syme Socket Prostheses Under General Loading
}

\author{
Prof.Dr. Muhsin J. Jweeg \\ College of Eng. Univ. of Al-Nahrain
}

\author{
Bakr Nori Al-Hassan \\ College of
}

Eng. Univ. of Mosul

\begin{abstract}
It is important to study Syme socket structure with respect to its strength. Due to the end stump deformity of the Syme's amputee, socket must has an opening (cutout) provided either posteriorilly or medially depending on the experience of the technicians.

This work is carried out numerically and experimentally to find out which side of socket, the opening should be provided, and to know the best shape should the opening have; rectangular or circular shape.

Numerical solutions have proved that the posterior opening is more desirable than the medial side opening, While rectangular shape of opening is better than the circular one.

In order to verify the obtained results, two similar models are constructed having different location of opening. The two sockets tested experimentally using strain gage technique.

Key words: Syme, Socket, Stress Analysis, Ansys Software, Biomechanics.

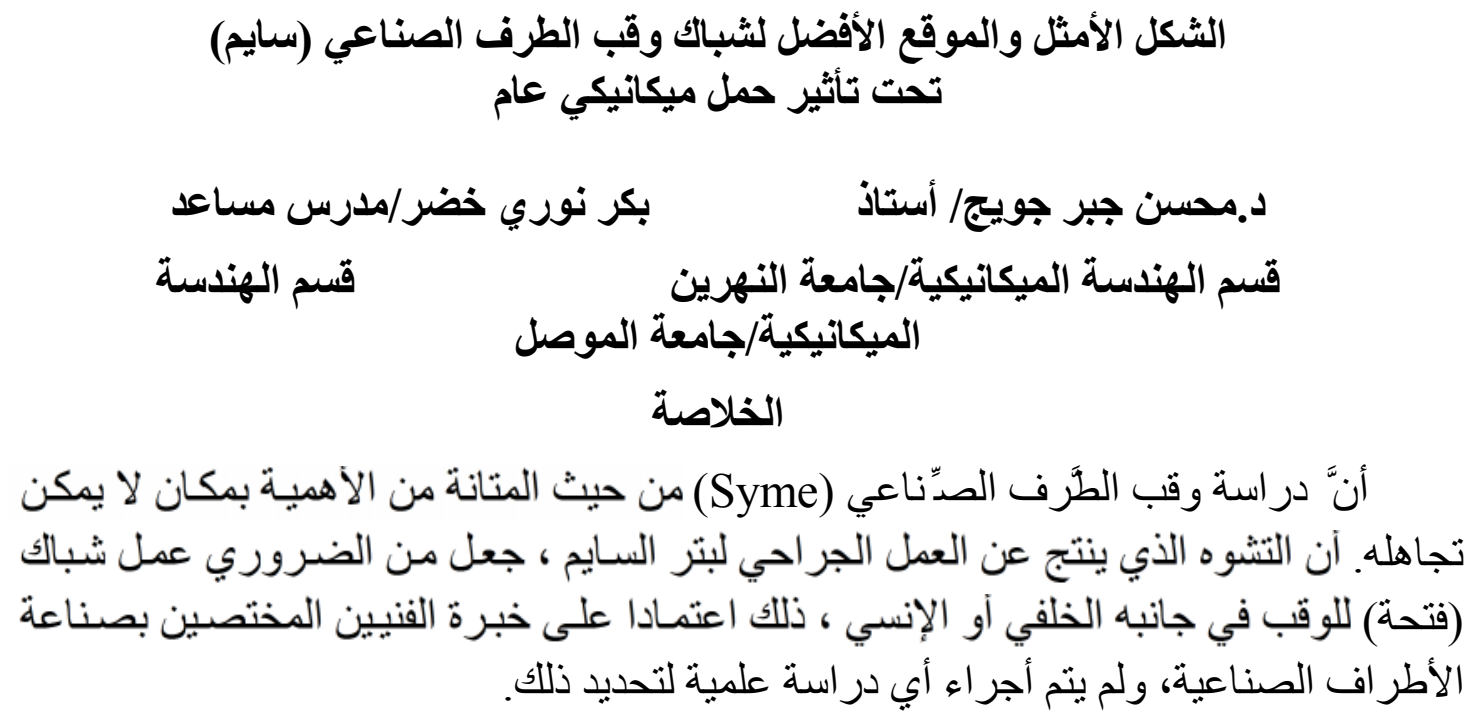

الخلاصة

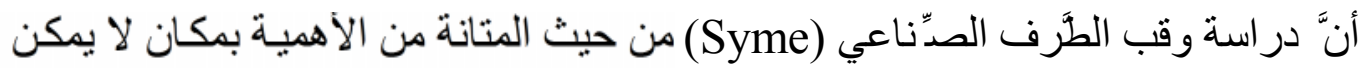

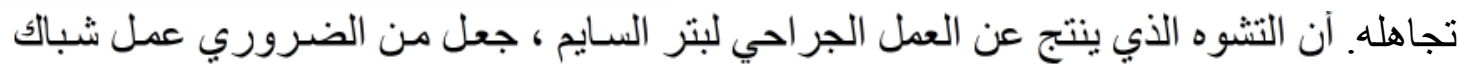

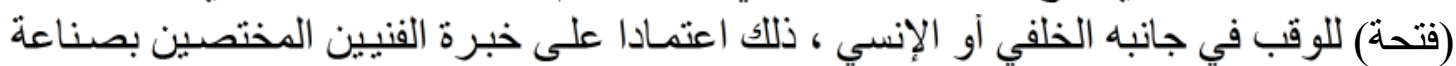
الأطر اف الصناعية، ولم يتم أجر اء أي دراسة الأبي علمية لتحديد ذلك. 
تَضمَّنت الدر اسةَ تحليلا عملياً و عددياً لمعرفة الثكل الأمثل و الموقع الأفضل لثباك وقب

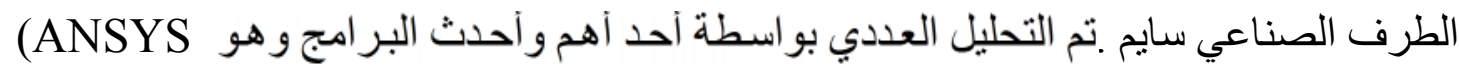
software) المستطيل للنافذة عن الثكل الدائري.

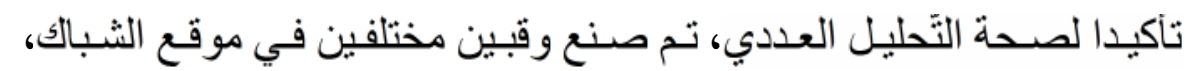

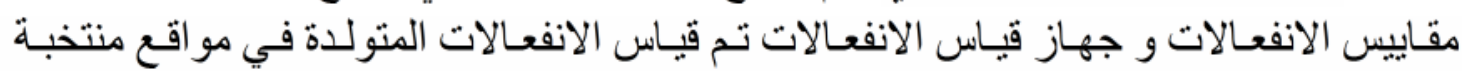
للوقبين، وقد أظهرت القر اءات تطابقا كبير ا مع نتائج التحليل العددي.

\section{Nomenclature:}

Received 25 Sep. 2006 


\begin{tabular}{|c|c|}
\hline Symbol & Definition \\
\hline$A_{p}$ & $\begin{array}{l}\text { Stump force corresponding and parallel to floor reaction force } \\
F_{r} \text { in }(N) \text {. }\end{array}$ \\
\hline$A V, L V$ & Anterior and lateral view. \\
\hline c.g. & Center of gravity of the human body. \\
\hline$d$ & Estimated distance between the two forces of $F_{x 1}$ and $F_{x 2}$ in $(\mathrm{cm})$ \\
\hline$E$ & Modulus of elasticity in (MPa). \\
\hline$f f$ & Length of foot in $(\mathrm{cm})$ \\
\hline$F_{r}$ & Reaction force in $(N)$ \\
\hline$F_{x 1}, F_{x 2}$ & $\begin{array}{l}\text { Anterior proximal and distal posterior forces used in ANSYS } \\
\text { program in }(N) .\end{array}$ \\
\hline G & Modulus of rigidity in $(\mathrm{MPa})$ \\
\hline$P$ & Applied load in tensile test in $(N)$ \\
\hline$P S M$ & Syme socket made of Polypropylene with medial cutout. \\
\hline$P S P_{\text {cir }}$ & $\begin{array}{l}\text { Syme socket made of Polypropylene with posterior circular } \\
\text { cutout. }\end{array}$ \\
\hline$P S P$ & Syme socket made of Polypropylene with posterior cutout. \\
\hline$S_{x, y, z}$ & $\begin{array}{l}\text { Stress developed in the Syme socket in } x, y \text { and } z \text {-direction in } \\
\left(N / m^{2}\right) \text {. }\end{array}$ \\
\hline$S_{1,2,3}$ & $\begin{array}{l}1^{\text {st }} 2^{\text {nd }} \text { and } 3^{\text {rd }} \text { principal stresses developed in the Syme socket in } \\
\left(\mathrm{N} / \mathrm{m}^{2}\right) \text {. }\end{array}$ \\
\hline$s_{1}, s_{2}$ & $\begin{array}{l}\text { A couple proximal anterior and distal posterior forces } \\
\text { countering the prosthesis to rotate clockwise. }\end{array}$ \\
\hline$U_{x, y, z}$ & Deflections of Syme socket in $x, y$ and $z$-direction in $(m)$. \\
\hline $\operatorname{Rot}_{x, y, z}$ & Rotations of Syme socket in $x, y$ and $z$-direction in $(m)$. \\
\hline$w$ & The body weight in $(N)$ \\
\hline$\theta$ & $\begin{array}{l}\text { Angle between reaction force and the normal as viewed laterally } \\
\text { in (deg rees). }\end{array}$ \\
\hline$\varepsilon$ & Transverse strain developed in the tensile test specimens in $(\mu \varepsilon)$. \\
\hline$\varepsilon_{x, y, z}$ & $\begin{array}{l}\text { Strains developed in the Syme socket in } x, y \text { and } z \text {-direction in } \\
(\mu \varepsilon) \text {. }\end{array}$ \\
\hline$\varepsilon_{1,2,3}$ & $\begin{array}{l}1^{\text {st }}, 2^{\text {nd }} \text { and } 3^{\text {rd }} \text { principal strains developed in the Syme socket in } \\
(\mu \varepsilon) \text {. }\end{array}$ \\
\hline$v$ & Poisson's ratio. \\
\hline
\end{tabular}




\section{Introduction}

The Syme amputation results in a stump with a bulbous end represent a problem in designing prosthesis. The most widely used Syme prosthesis is the one with a panel opening (cutout) is provided at the narrow section of the socket either on the posterior or medial side to allow entry of the bulbous stump end inside. ${ }^{[1]}$

The reasons for adopting this study are:

1. There are thousands of amputees in Iraq due to the wars. This means more artificial limbs must be manufactured with low cost.

2. Syme amputees present high number with respect to other type of amputees, also the Syme prostheses can not be continued for along time.

3. There are no researches that predict stresses in the socket. The objective of this work is to investigate the optimum shape and the location of panel opening: posteriorlly or medially in Syme prostheses under general loading.

Three models of sockets are suggested and has been solved; a socket made of polypropylene material with posterior rectangular opening denoted by (PSP), a socket made of polypropylene with medial rectangular opening denoted by $(P S M)$, a socket made of polypropylene with posterior circular opening denoted by $\left(P S P_{c i r}\right)$. In each of these three models, the stress distribution through the sockets is detected by applying the software package ANSYS.

After that, sockets of (PSP) and (PSM) models are fabricated, both have thickness of $4 \mathrm{~mm}$, and the experimental stress analysis proceeded on the two sockets with the strain gage technique.

Tensile test is carried out to find the mechanical properties of the socket materials that is a thermoplastic type polypropylene. 


\section{Biomechanical force analysis:}

The determination of the biomechanical forces of Syme prosthesis starts with analyzing the human gate stage at which analysis proceeded.

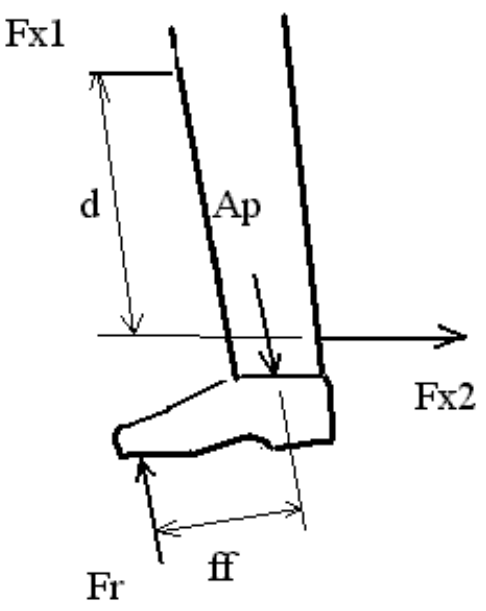

Figure (1) Stump socket forces and reaction forces.

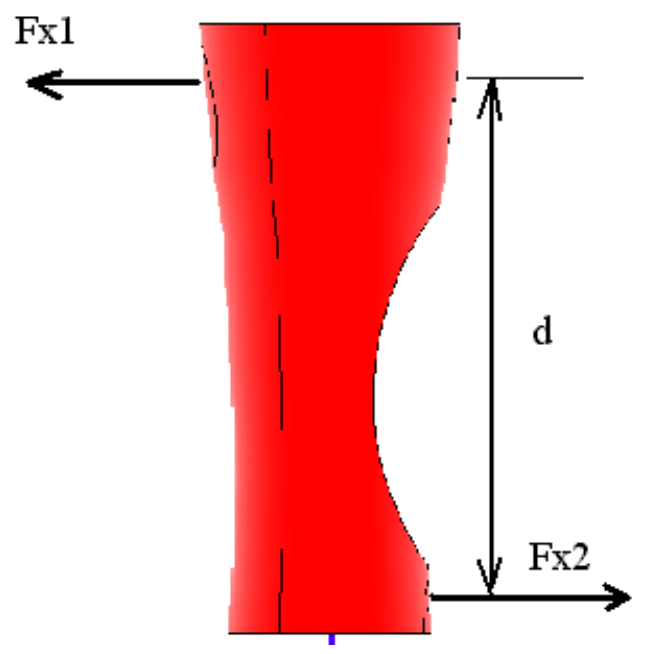

Figure (2) Equivalent model of Syme socket to solve by ANSYS.

The heel off stage is the appropriate stage because of all most the body weight is on the stance leg. ${ }^{[1]}$

The force of gravity acts on the body and its component parts at all times. The limb may be regarded therefore, as weightless levers of the body under static condition. ${ }^{[2]}$

Fig.(1) Shows the forces acting on the prosthesis so that the estimated floor reaction $F_{r}$ and the corresponding stump force $A_{p}$ which is actually parallel to $F_{r}$ make a couple cause the prostheses to rotate clockwise on the stump. The actual moment of forces is given by the term $F_{r} \times f f$ (or by the term $A_{p} \times d$, since $A_{p}=F_{r}$ ). This tendency to rotate is countered by another force couple $\mathrm{F}_{\mathrm{x} 1}$ and $\mathrm{F}_{\mathrm{x} 2}$ (stump socket forces) which produce a counter clockwise moment equal to $F_{x 1} \times d\left(\right.$ or $\left.F_{x 2} \times d\right)$, then this can be simply stated as ${ }^{[4]}$ :

$$
\begin{aligned}
& F_{r} \times f f=F_{x 1} \times d \\
& F_{x 1}=F_{r} \times \frac{f f}{d} .
\end{aligned}
$$


Its more convenient to convert the schematic shown in Fig.(1), Into another model by fixing it at the joining section of socket with foot as shown in Fig.(2) this is suitable to set boundary condition equal to zero displacement and zero rotations at that joint which is more convenient for finite element analysis, the only existing forces here are $F_{x 1}$ and $F_{x 2}$.

To obtain values of $\mathrm{F}_{\mathrm{x} 1}$ and $\mathrm{F}_{\mathrm{x} 2}$, the following assumptions should be made:

ff Estimated to about $15 \mathrm{~cm}$ and d equal to $22 \mathrm{~cm}$.

$$
A_{p}=w^{[4]}
$$

From equation (3.1):

$$
F_{x 1}=w \times \frac{f f}{d}
$$

Where $w$ is taken as the patient weight and equal to $m g=981 \mathrm{~N}$. Substituting to get $F_{x 1}=670=F_{x 2}$

The above parameters $F_{x 1}, F_{x 2}$ and the boundary condition of $U_{x}, U_{y}, U_{z}, \operatorname{Rot}_{x}, \operatorname{Rot}_{y}$ and $\operatorname{Rot}_{z}$ are inputs to solve with the ANSYS package software.

\section{Computer Methodology}

Recently, thousands of engineering problems have been solved effectively using software packages. The packages such as ANSYS, NASTRAN...etc. have been constructed depending on the finite element analysis technique as powerful tool to obtain solution for complicated problems where analytical solution can not be applied.

In this work, the ANSYS program is applied to solve three Syme socket models: $P S P, P S M$ and $P S P_{c i r}$.

The element defined by four nodes, four thicknesses and elastic foundation stiffness. The element $\mathrm{x}$-axis may be rotated by angle $\theta$ (in degree). In the Syme socket model; the elastic foundation stiffness are bypassed in the element, if the model is not subjected to foundation 
effects. The thickness of the element assumed constant over the area of the element. ${ }^{[3]}$

The following mechanical properties of the Syme socket polypropylene material are developed from the tensile test achieved for this purpose:

$E=1170 \mathrm{MPa} \quad, G=440 \mathrm{MPa}$ and $\quad v=0.33$

The density of the socket material $\rho=900 \mathrm{~kg} / \mathrm{m}^{3}$ (calculated).

In order to get the dimensions for computer drawings, the dimensions of the fabricated sockets are measured. Its assumed to be symmetrical about the patient limb axis (y), and the circumferentials measured spaced by $(1 \mathrm{~cm})$ in y-direction. The socket shape is created with posterior or medial; circular or rectangular opening by ANSYS power graph capabilities.

The program is solved with the best mesh density obtained, socket thickness of $4 \mathrm{~mm}$ and loading conditions corresponding patient weight at heel off gait stage.

\section{Tensile properties of polypropylene:}

In order to obtain the mechanical properties of the socket polypropylene material, tensile test is conducted on specimens that are prepared from the socket. Though the mechanical properties of polypropylene may be obtained from plastic charts or providers, the mechanical properties vary throughout fabrication processes of socket because of both heating and drawing effects.

The specimen dimensions are confirmed according to the American society for Testing and Materials (ASTM D638-99). Five samples were fabricated and prepared in the same way. The results obtained represent the average of five replicates. ${ }^{[4]}$

The Modulus of elasticity obtained is equal to $1170 \mathrm{MPa}$, the yield is equal to $32.96 \mathrm{MPa}$. and the poisson's ratio $v$ that is obtained equal to 0.33 . 


\section{Experimental work:}

One of the patients in Prosthetics and Orthotics workshop in Mosul (400-km north of Baghdad/Iraq) was chosen. The patient was young of $100-\mathrm{kg}$ mass and a height of $1.70 \mathrm{~m}$, the patient was a Syme amputation carried out on his left leg in 1987.

Two sockets were fabricated; one has a posterior rectangular opening and the second has a medial rectangular opening. The two sockets have same dimensions and made of the same material (polypropylene), same thickness $(4 \mathrm{~mm})$ and fitted with the same foot size and tested under the same loading conditions.

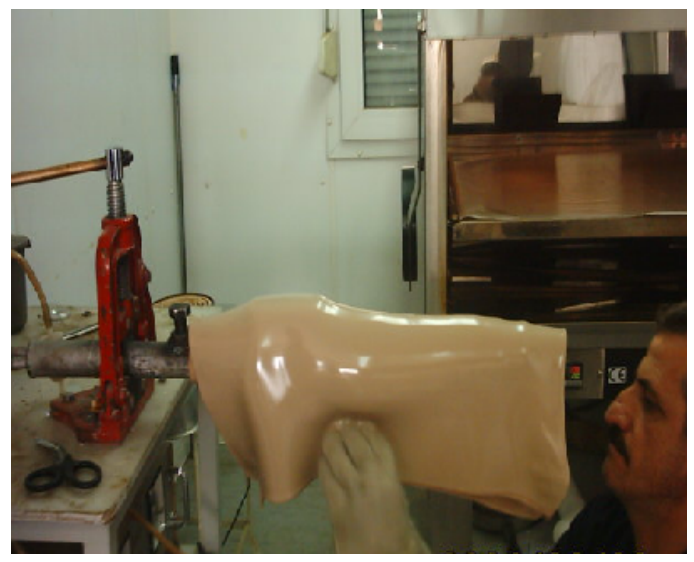

Figure (3) The positive cast covered location at

by the heated polypropylene sheet

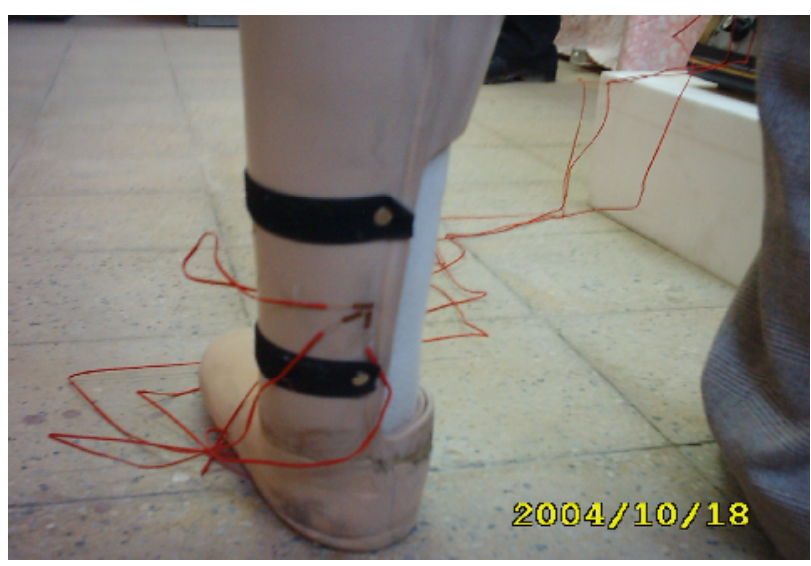

Figure (4) Strain gages

PSM socket at Test State

\section{Strain test:}

In order to find strains at specified points on the two sockets experimentally, the strain gages technique was used. The strain gage converts any change in the dimension (elongation or compression) in to ohmic resistance, which can be accurately measured by whetstone bridge circuit to the exact magnitude of mechanical strain.

The strain gages are attached to the surface of the socket at opening edge, at a convenient location to study and specify existing stresses to compare with the numerical results. The strain gage used is TML Foil 
strain gage (GF-series) manufactured by Tokyo Sokki Kenkyujo Co. which is designed explicitly for use on materials having a low modulus of elasticity. This is convenient for plastics especially for polypropylene socket material. These types of strain gages greatly reduce the reinforcement effects, which are exhibited by normal strain gages. The strain gages are installed using standard bounding procedure. However, an abrasive paper grade 500 is used to increase the cement contact area. Then its cleaned with an alcohol solvent to remove dirts from the socket surface. A small quantity of adhesive is dropped on the backside of "GF"sereis-gage and the gage is plastered on a clean socket surface. The plastered gage is covered with a polyethylene sheet and has kept pressed strongly with a thump, and then the gage has been set about one minute. The Veshay strain meter manufactured by Veshay Co. is used. The instrument registers the magnitude of strain taken directly from the pointer. For each socket, a total of three strain gauges are installed at the specific locations of the opening cutout; one in x-direction, another in ydirection and the third in $45^{\circ}$ with $\mathrm{x}$-axis. The installed arrangement of the strain gauges on each socket are as follows:

1. Socket with posterior cutout $(P S P)$ : Three strain gauges in $\mathrm{x}, \mathrm{y}$ and $45^{\circ}$ with $\mathrm{x}$-axis installed at lateral side of the opening cutout.

2. Socket with medial cutout $P S M$ : Three strain gauges in $\mathrm{x}, \mathrm{y}$ and $45^{\circ}$ installed at anterior side of the cutout as shown in Fig. 10.

Each strain gauge records the strain in that axis directly at heel off stage of gait as shown in Fig.(4).

The heel off phase is implemented as a case for experimental test. It represents the condition which socket bears the total patient weight. Consequentially, the applied load is the maximum to be taken in design considerations. Each case is tested three times, the results are then averaged. The loading force on the socket is the patent weight which was $980 \mathrm{~N}$.

To calculate strains from strain gage readings obtained from three gages rectangular rosette, ${ }^{[5]}$

$$
\varepsilon_{\theta}=\frac{\varepsilon_{x}+\varepsilon_{y}}{2}+\frac{\varepsilon_{x}-\varepsilon_{y}}{2} \cos 2 \theta+\frac{\gamma_{x y}}{2} \sin 2 \theta
$$


Because the $\mathrm{x}$-axis is chosen to coincide with $\theta=0$, therefore, the calculations are simplified in each application of the equation for the three values of $(\theta)$ of the rosette gage.

The readings of $\varepsilon_{0}$ and $\varepsilon_{90}$ are representing $\varepsilon_{\mathrm{x}}, \varepsilon_{\mathrm{y}}$ respectively.

Then principal strains $\varepsilon_{1}, \varepsilon_{2}$ are calculated from the relations:

$$
\varepsilon_{1}=\frac{\varepsilon_{x}+\varepsilon_{y}}{2}+1 / 2 \sqrt{\left(\varepsilon_{x}-\varepsilon_{y}\right)^{2}+\gamma_{x y}^{2}}
$$

$$
\varepsilon_{2}=\frac{\varepsilon_{x}+\varepsilon_{y}}{2}-1 / 2 \sqrt{\left(\varepsilon_{x}-\varepsilon_{y}\right)^{2}+\gamma_{x y}^{2}}
$$

\section{Results}

Syme socket material used in the Prosthetic and Orthotic Center in Mosul made of a thermoplastic material type polypropylene. Typical results of the test are: the Young modulus of the material is equal to 1170 $M P a$, while that for the polypropylene sheets provided by the supplier is $1400 \mathrm{MPa}$ [6], the ultimate tensile strength is $32.69 \mathrm{MPa}$ and the Poisson's ratio is 0.33 . Each values of the above represents the average of five replicates.

Typical tensile stress strain curve of the Syme socket material is shown in Fig. (5). The linear portion of the stress strain curve is very small and has occurred rapidly. The modulus of rigidity is then calculated ${ }^{[5]}$ :

$$
\begin{array}{r}
G=\frac{E}{2(1+v)} \\
G=440 \mathrm{MPa}
\end{array}
$$

Table (1) Shows maximum deflections, strains and stresses (components and principals) developed in the $P S P$ and $P S P_{c i r}$ socket at the same thickness as a comparison between the two shapes of socket openings; rectangular and circular. The table informs clearly the preferable of $P S P$ socket. Table (2) shows the same behavior between the PSP and PSM sockets, the big difference in the values tells the unsuitability of the PSM socket. 
Fig.(6) shows the maximum stresses developed in the socket of three models. It is shown as the thickness of socket increases the stress decreases. The same thing is happening with maximum deflections as shown in Fig.(7) where the maximum deflection decreases when the socket thickness increases.

Generally, the stresses and deflections developed in the socket with posterior cutout are smaller than that in medial opening. The shape of the opening also affects on the stresses and deflections, where the rectangular shape develops somewhat less stresses and deflections than circular shape of opening. The curves of maximum stresses of the PSP and $P S P_{c i r}$ may be close together, but could be decided that the $P S P$ is better. The two figures stress that the medial opening is unsuitable side to locate cutting out.

Fig.(8) shows the effect of socket thickness (t) on the stiffness to weight ratio for the models of $P S P, P S M$ and $P S P_{c i r}$ sockets under unit load of $F x$. It is clearly shown that the PSP model is in high level with respect to the rest. The PSM curve is close to the horizontal axis because it has small values of stiffness to weight ratio.

Fig.(9) shows the stiffness weight ratio of the sockets under unit loads of $F y$. The $P S P$ and $P S P_{c i r}$ are also close but PSP socket still has stiffness values greater than the $P S P_{c i r}$.

\section{Case study:}

Two Syme sockets one with posterior opening and the other with medial opening are fabricated and used by a patient of $100-\mathrm{kg}$ mass. Other proposed socket made of polypropylene, but with circular opening. The loading condition has been taken at heel off gait stage. The following figures (10) to (15) show the contour plots of deflections and strains in different directions.

Table (3) shows the experimental strains and stresses developed at the selected locations on the opening edge for the two fabricated socket models of PSP and PSM. The table contains also the corresponding strains obtained from the numerical solution of the same models.

The strains obtained numerically by the ANSYS program differs from that obtained experimentally by; $30 \%$ for strain in x-direction $\left(\varepsilon_{\mathrm{x}}\right), 18 \%$ for the strain $\left(\varepsilon_{y}\right), 20 \%$ for the first principal strain $\left(\varepsilon_{1}\right)$, and $23 \%$ for the second principal strain $\left(\varepsilon_{2}\right)$.

In the PSM socket; the strains developed numerically differs from that obtained experimentally by; $17 \%$ for $\left(\varepsilon_{\mathrm{x}}\right), 16 \%$ for $\left(\varepsilon_{\mathrm{y}}\right), 40 \%$ for $\left(\varepsilon_{1}\right)$ and

10

$\left(\varepsilon_{2}\right)$.

$\%$

for

The above percentages variations of the numerical results from that developed experimentally belongs to many reasons, such as the shape 
approximations, biomechanical force approximation of load conditions, and because the numerical ANSYS program based on the finite element method which is in turn an approximate method for solving. Generally the numerical errors could be within a reasonable range and the numerical results may be countable on.

\begin{tabular}{|c|c|c|c|c|c|c|c|c|}
\hline$\frac{\text { Socke }}{\underline{t}}$ & $\begin{array}{l}\mathrm{U}_{\mathrm{x}} \\
* 10^{6} \\
(\mathrm{~m})\end{array}$ & $\begin{array}{l}\mathrm{U}_{\mathrm{y}} \\
* 10^{6} \\
(\mathrm{~m})\end{array}$ & $\begin{array}{l}\mathrm{U}_{\mathrm{z}} \\
* 10^{6} \\
(\mathrm{~m})\end{array}$ & $\begin{array}{l}\varepsilon_{\mathrm{x}} \\
(\varepsilon)\end{array}$ & $\begin{array}{l}\varepsilon_{\mathrm{y}} \\
(\varepsilon)\end{array}$ & $\begin{array}{l}\varepsilon_{\mathrm{z}} \\
(\varepsilon)\end{array}$ & $\begin{array}{l}\mathrm{S}_{\mathrm{x}} \\
(M P a)\end{array}$ & $\begin{array}{l}\mathrm{S}_{\mathrm{y}} \\
(M P a)\end{array}$ \\
\hline$P S P$ & 35.5 & 7.88 & 26.4 & -335 & -334 & 411 & 2.28 & -4.94 \\
\hline$P S P_{c i r}$ & 112 & 34.1 & 26.1 & -350 & -346 & -359 & 0.635 & 5.02 \\
\hline $\begin{array}{l}\text { Socke } \\
\text { t }\end{array}$ & $\begin{array}{l}\mathrm{S}_{\mathrm{Z}} \\
(M P a)\end{array}$ & $\begin{array}{l}\varepsilon_{1} \\
(\varepsilon)\end{array}$ & $\begin{array}{l}\varepsilon_{2} \\
(\varepsilon)\end{array}$ & $\begin{array}{l}\varepsilon_{3} \\
(\varepsilon)\end{array}$ & $\begin{array}{l}\mathrm{S}_{1} \\
(M P a)\end{array}$ & $\begin{array}{l}\mathrm{S}_{2} \\
(M P a)\end{array}$ & $\begin{array}{l}\mathrm{S}_{3} \\
(M P a)\end{array}$ & $\begin{array}{l}\varepsilon_{\text {vonmises }} \\
(\varepsilon)\end{array}$ \\
\hline$P S P$ & 5.75 & 411 & 303 & -349 & 5.76 & 4.93 & -4.97 & 712 \\
\hline$P S P_{c i r}$ & 5.98 & 429 & -308 & -361 & 5.98 & 5.1 & -5.18 & 738 \\
\hline
\end{tabular}

Table (1) Maximum deflections, strains, and stresses developed in the models of PSP and PSPcir. Sockets at thickness of $4 \mathrm{~mm}$. 


\begin{tabular}{|l|l|l|l|l|l|l|l|l|}
\hline Socket & $* 10^{6}$ & $* 10^{6}$ & $* 10^{6}$ & $\mathrm{U}_{\mathrm{x}}$ & $\varepsilon_{\mathrm{y}}$ & $\varepsilon_{\mathrm{z}}$ & $\mathrm{S}_{\mathrm{x}}$ & $\mathrm{S}_{\mathrm{y}}$ \\
$(\mathrm{m})$ & $(\mathrm{m})$ & $(\mathrm{m})$ & $(\varepsilon)$ & $(\varepsilon)$ & $(M P a)$ & $(M P a)$ \\
\hline$P S P$ & 35.5 & 7.88 & 26.4 & -335 & -334 & 411 & 2.28 & -4.94 \\
\hline$P S M$ & 1369 & -62.3 & 710 & -459 & 1161 & -995 & 2.87 & 12.3 \\
\hline Socket & $(M P a)$ & $(\varepsilon)$ & $(\varepsilon)$ & $(\varepsilon)$ & $(M P a)$ & $(M P a)$ & $(M P a)$ & $(\varepsilon)$ \\
\hline$P S P$ & 5.75 & 411 & 303 & -349 & 5.76 & 4.93 & -4.97 & 712 \\
\hline$P S M$ & -9.98 & 1369 & 390 & 1369 & 12.4 & 5.28 & -12.1 & 1616 \\
\hline
\end{tabular}

Table (2) Maximum deflections, strains, and stresses developed in the models of $P S P$ and $P S M$. Sockets at thickness of $4 \mathrm{~mm}$.

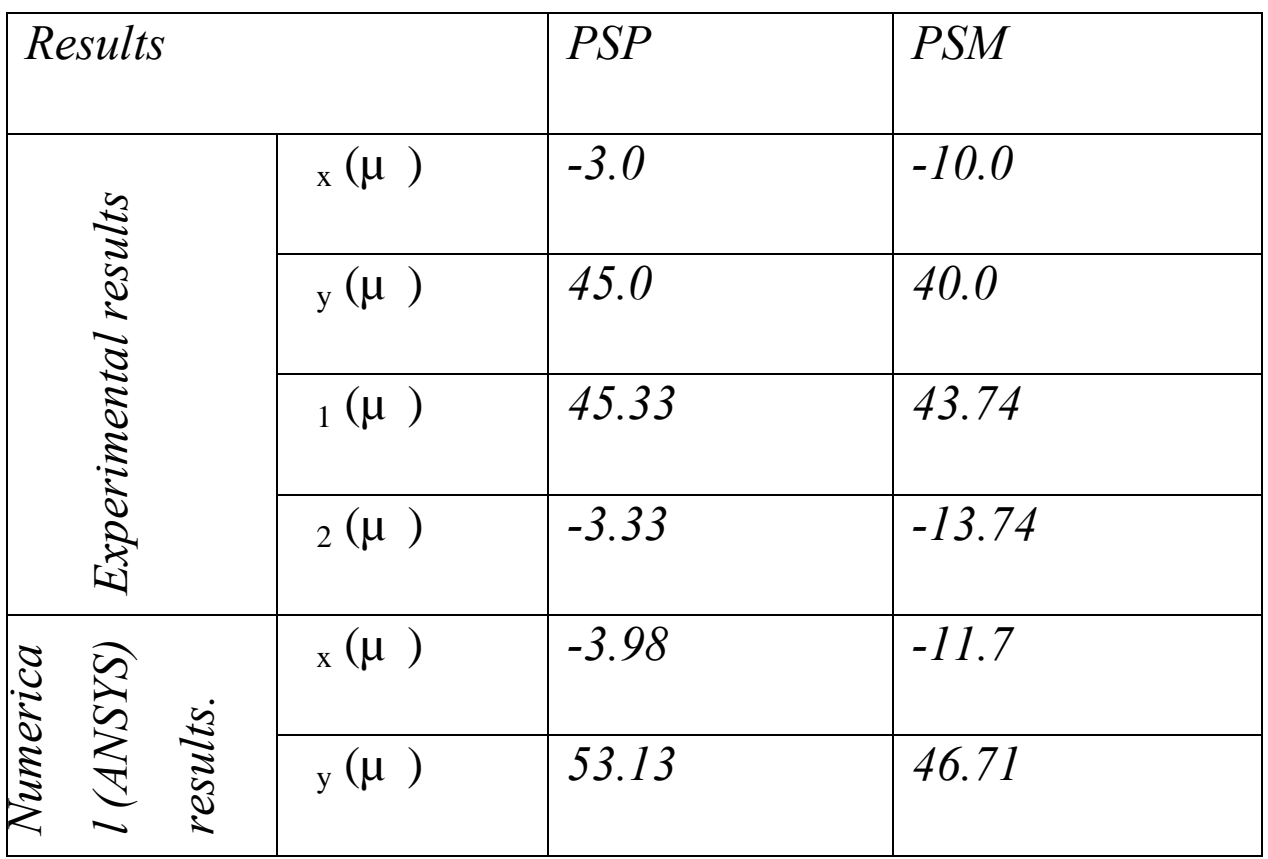




\begin{tabular}{|l|l|l|l|}
\hline & $\varepsilon_{1}(\varepsilon)$ & 54.94 & 61.4 \\
\cline { 2 - 4 } & $\varepsilon_{2}(\varepsilon)$ & -4.1 & -12.25 \\
\hline
\end{tabular}

Table (3) Experimental and numerical results at selected locations of the opening for the two models of PSP and PSM .

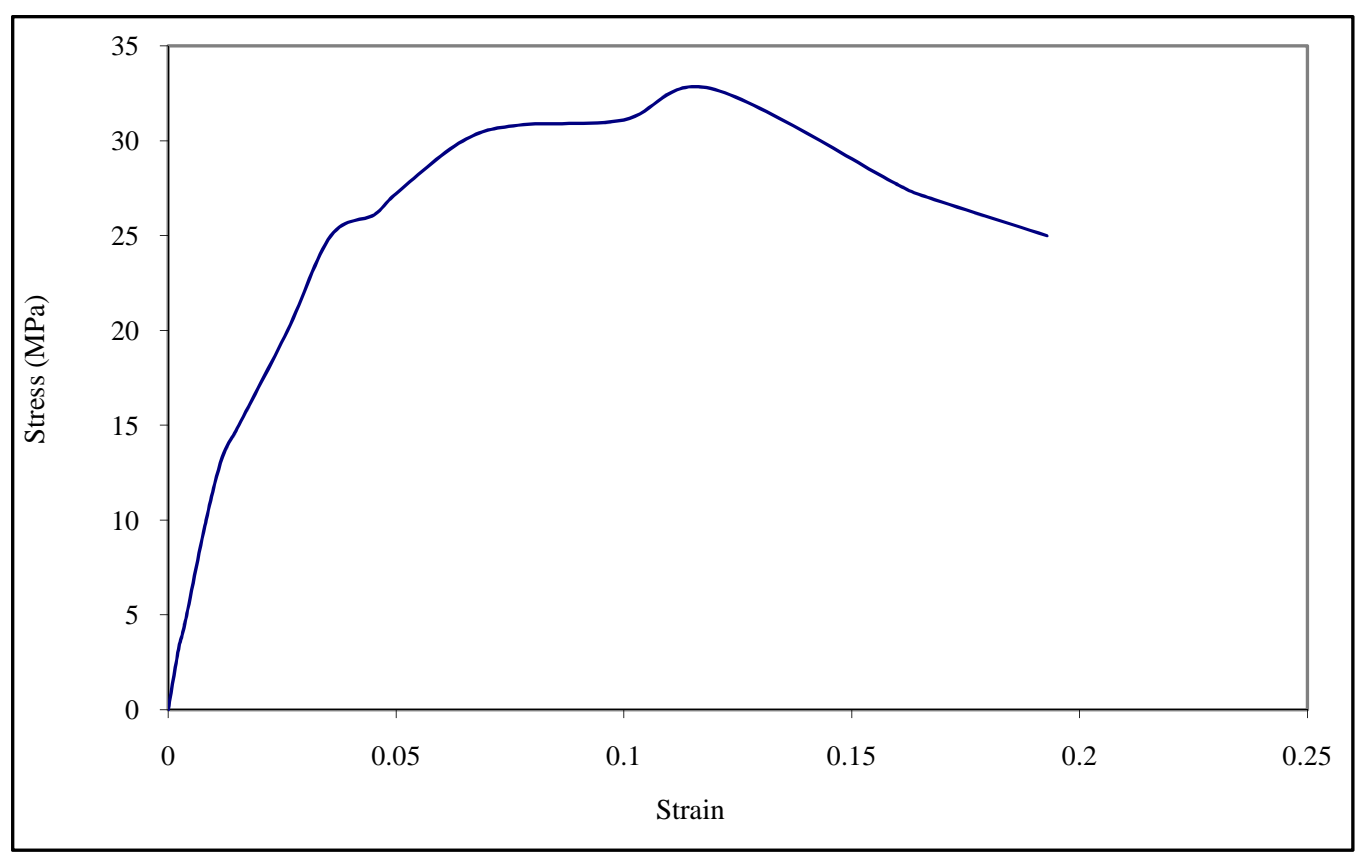

Figure 5 Stress strain curve for Syme socket material (Polypropylene) 


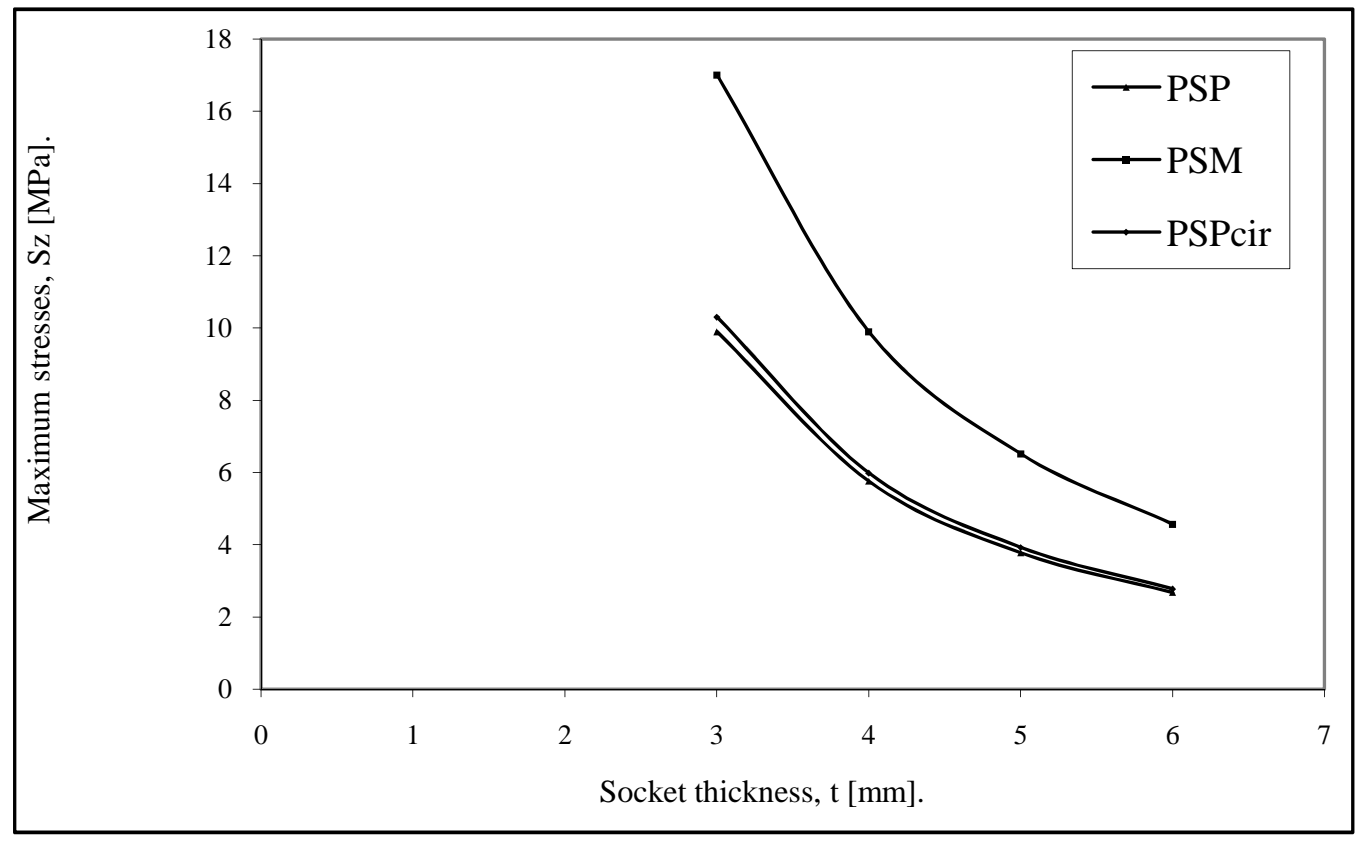

Figure 6 Effect of socket thickness on maximum stresses

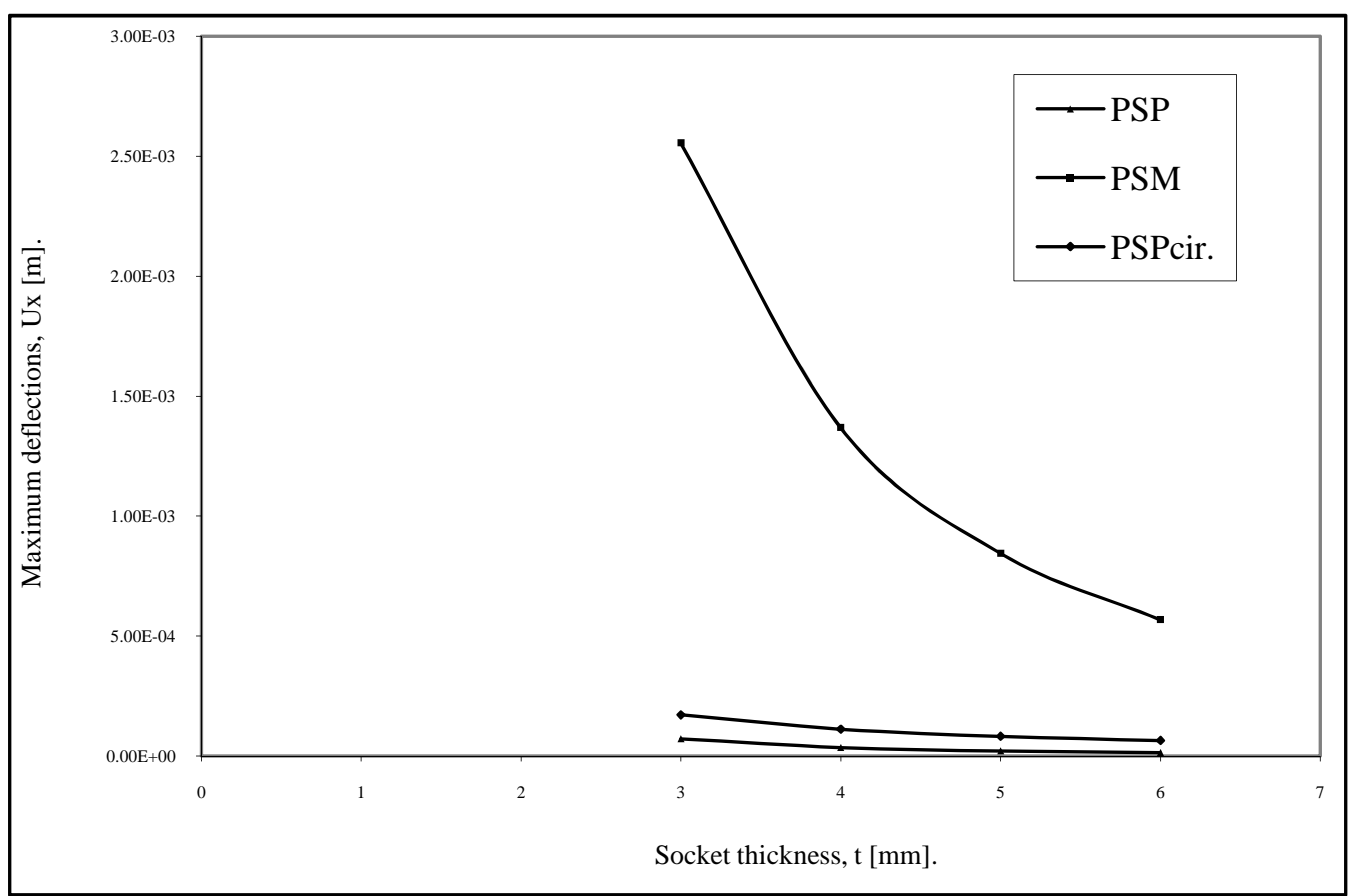

Figure 7 Effect of socket thickness on maximum deflections. 


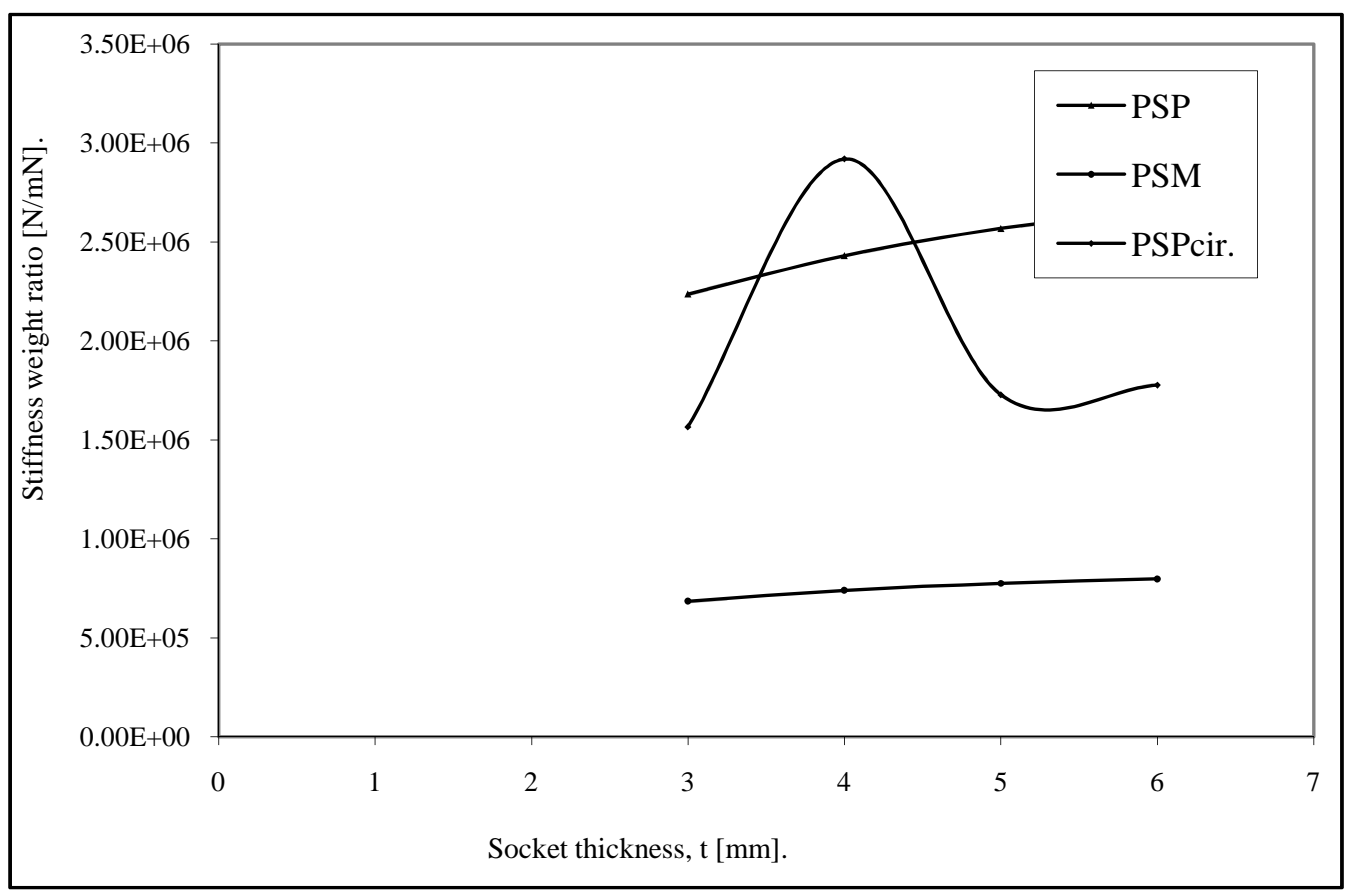

Figure 8 Effect of socket thickness on stiffness weight ratio

Under unit load of $F_{x}$.

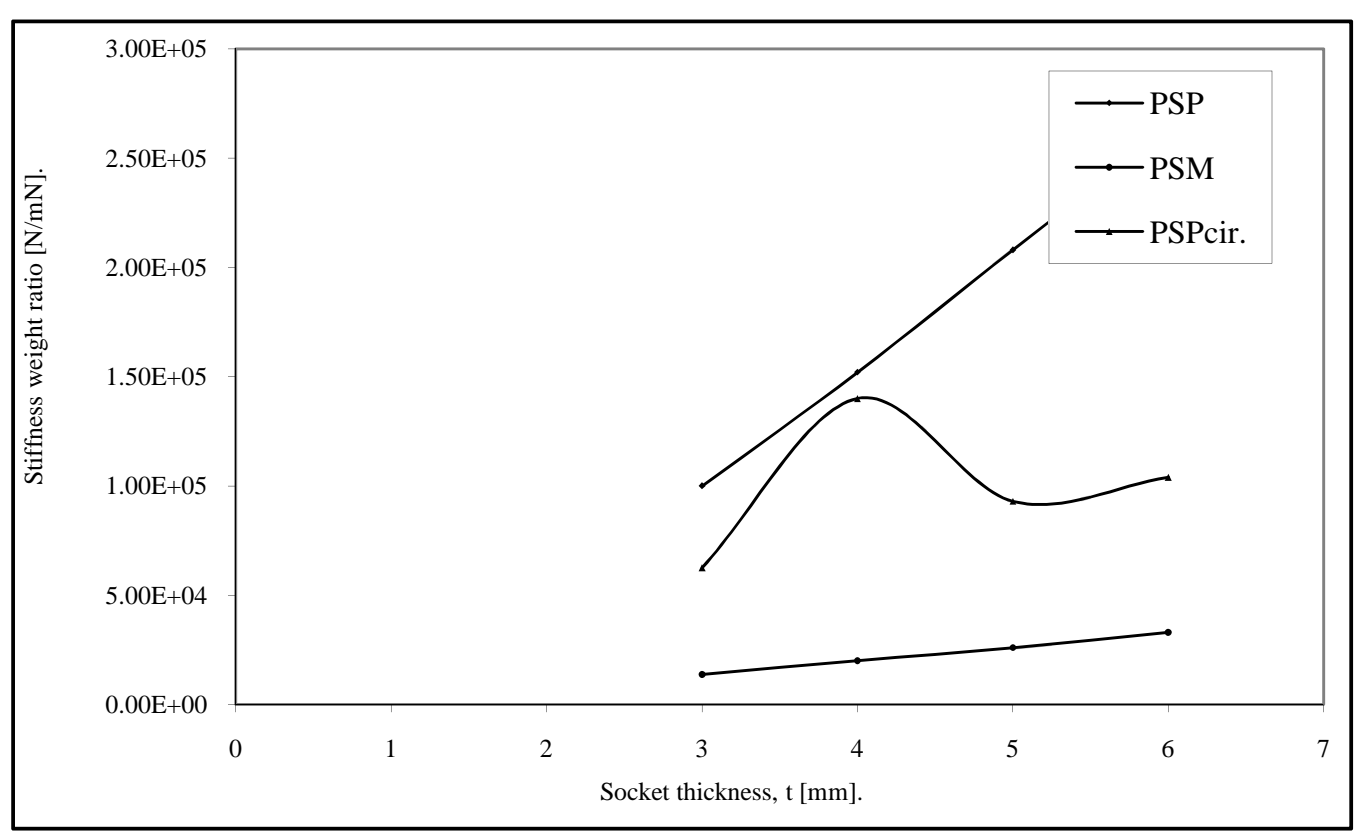


Figure 9 Effect of socket thickness on stiffness weight ratio

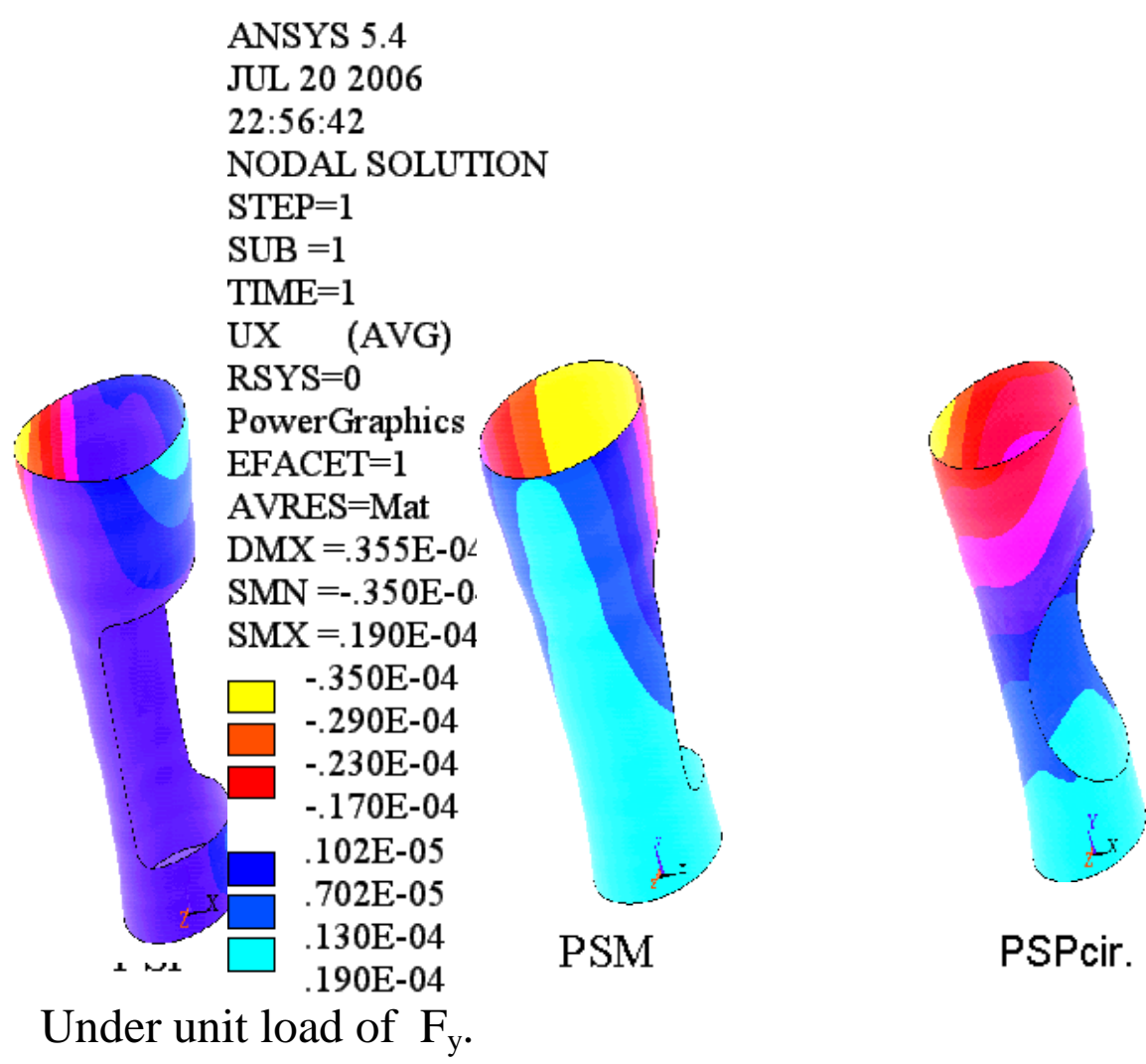

$\begin{array}{ll}\text { ANSYS 5.4 } & \text { ANSYS 5.4 } \\ \text { JUL 21 2006 } & \text { JUL 21 2006 } \\ \text { 19:51:22 } & \text { 19:58:00 } \\ \text { NODAL SOLUTION } & \text { NODAL SOLUTION } \\ \text { STEP }=1 & \text { STEP=1 } \\ \text { SUB }=1 & \text { SUB }=1 \\ \text { TIME }=1 & \text { TIME=1 } \\ \text { UX (AVG) } & \text { UX (AVG) } \\ \text { RSYS=0 } & \text { RSYS }=0 \\ \text { PowerGraphics } & \text { PowerGraphics } \\ \text { EFACET=1 } & \text { EFACET }=1 \\ \text { AVRES=Mat } & \text { AVRES=Mat } \\ \text { DMX }=.001369 & \text { DMX }=.112 \mathrm{E}-03 \\ \text { SMN }=-.001361 & \text { SMN }=-.110 \mathrm{E}-03 \\ \text { SMX }=.107 \mathrm{E}-04 & \text { SMX }=.101 \mathrm{E}-04\end{array}$


Figure (10) Contour lines of the maximum deflection $\left(U_{x}\right)$ in Syme socket models of $P S P, P S M$, and $P S P_{\text {cir }}$ under loading at heel off.

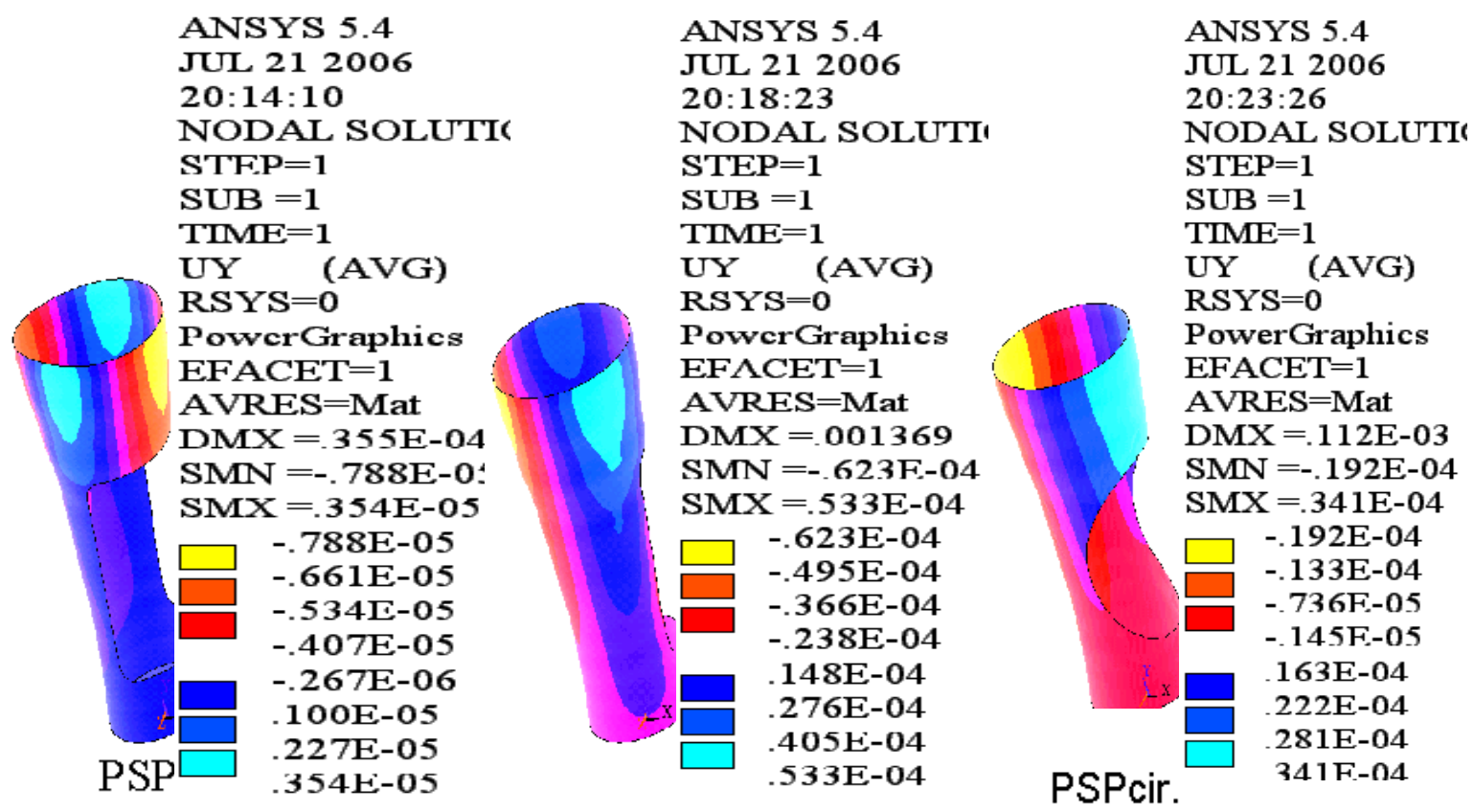

PSM

Figure (11) Contour lines of the deflection $U_{y}$ in Syme socket models of $P S P, P S M$, and $P S P_{\text {cir }}$ under loading at heel off. 


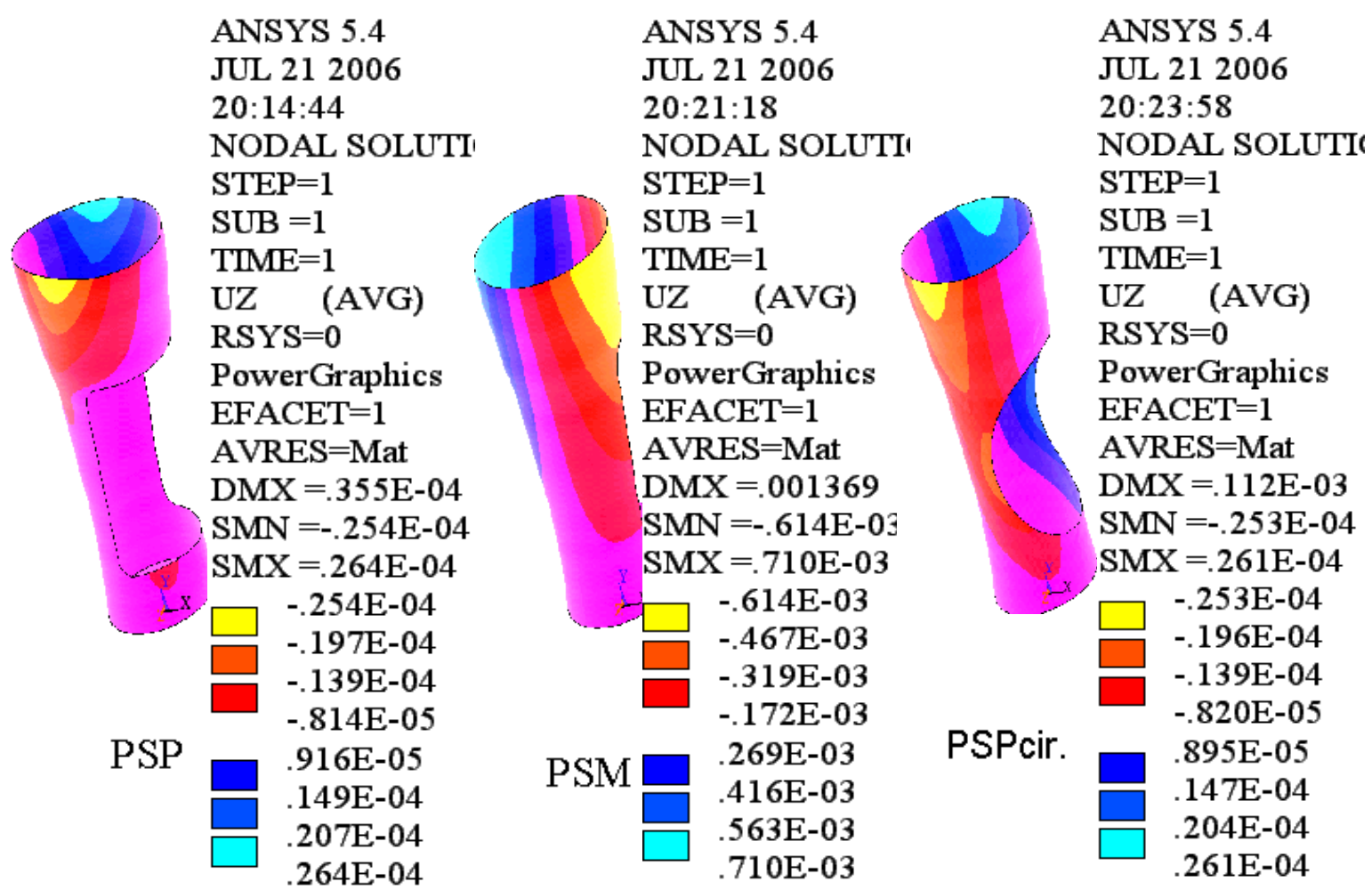

Figure (12) Contour lines of the deflection $U_{z}$ in Syme socket models of $P S P, P S M$, and $P S P_{\text {cir }}$ under loading at heel off.

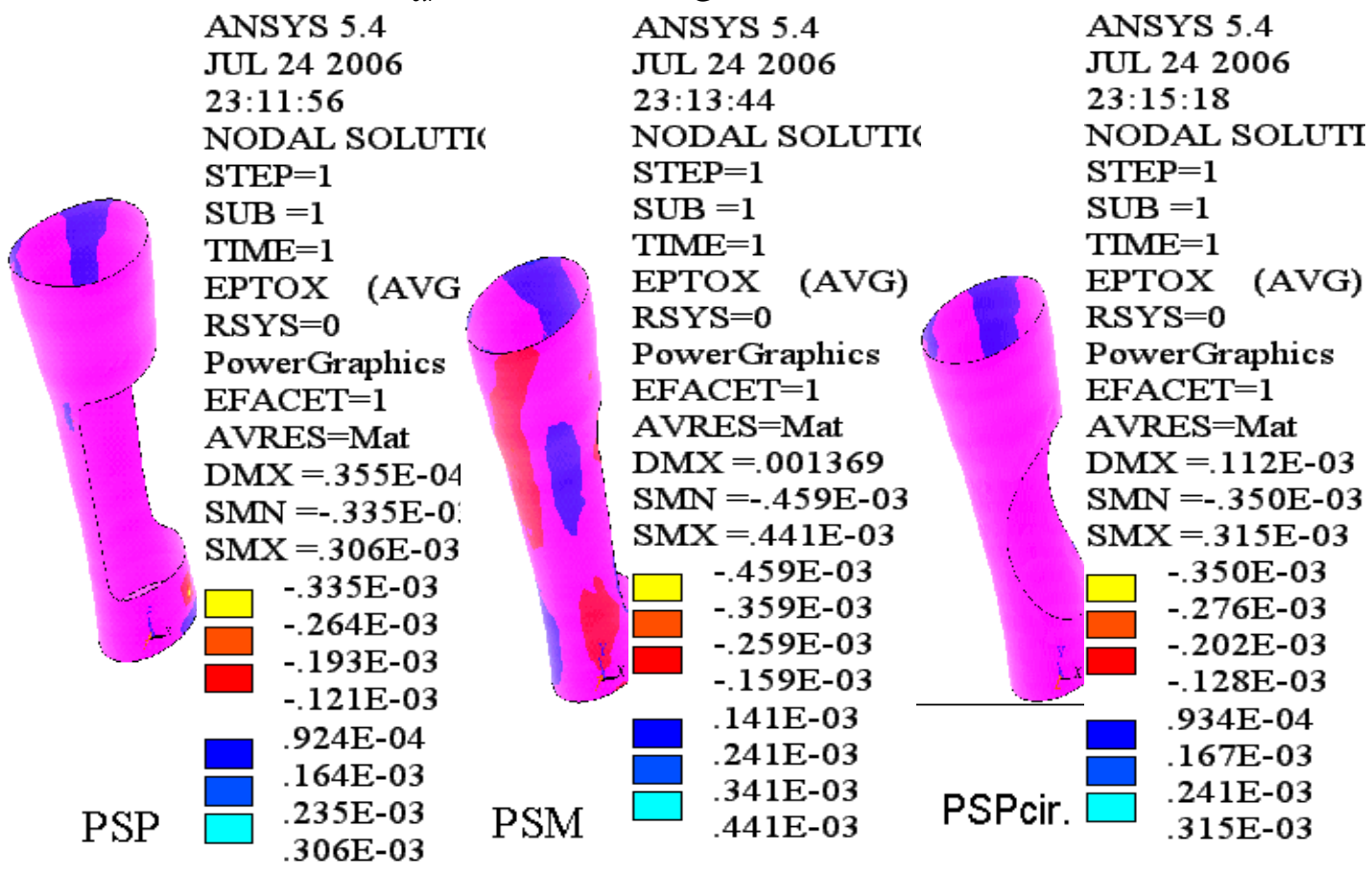

Figure (13) Contour lines of strains $\varepsilon_{\mathrm{x}}$ in Syme socket models of $P S P, P S M$, and $P S P_{c i r}$ under loading at heel off. 


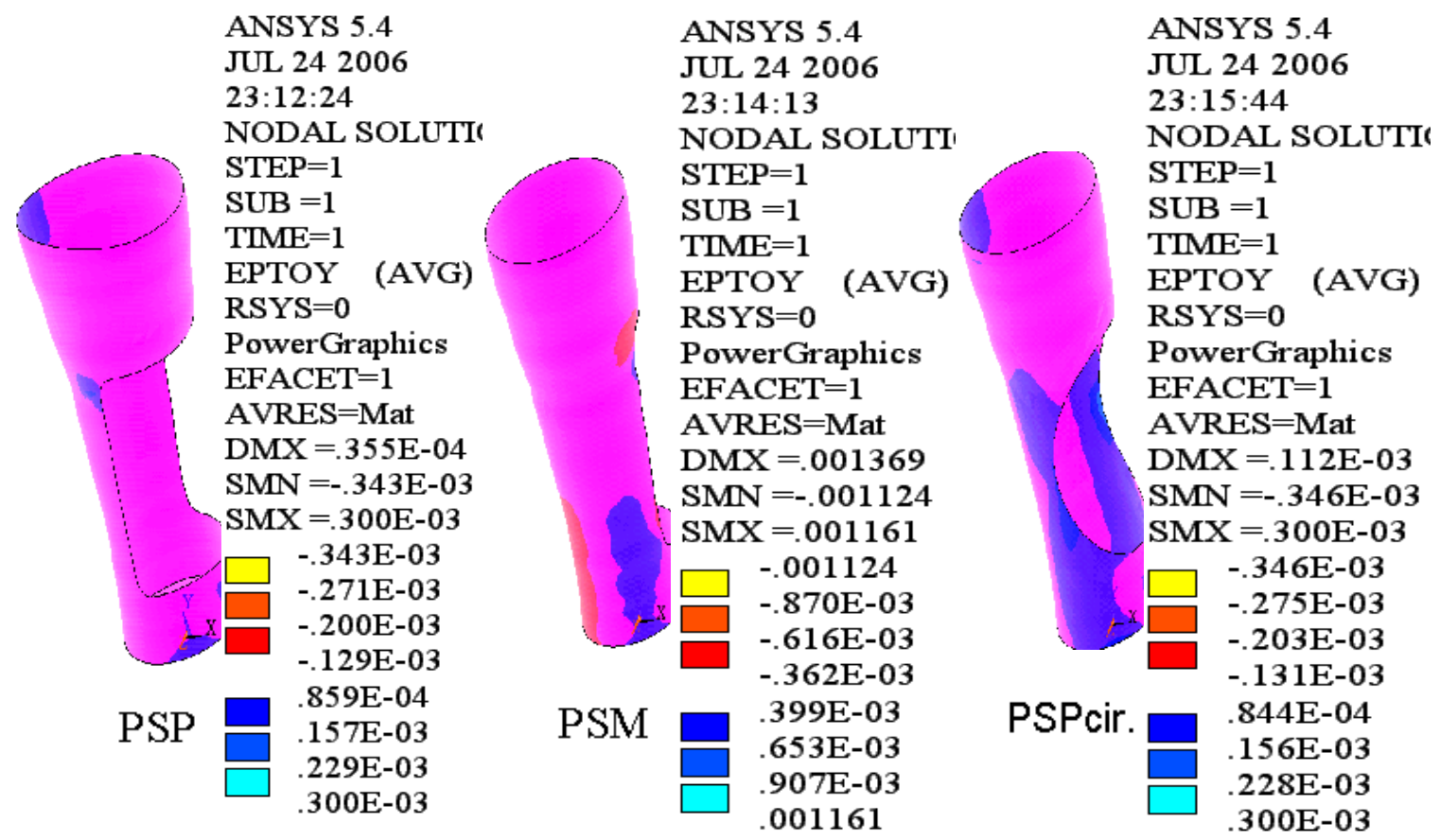

Figure (14) Contour lines of the strain $\varepsilon_{\mathrm{y}}$ in the Syme socket models of $P S P, P S M$, and $P S P_{\text {cir }}$ under loading at heel off.

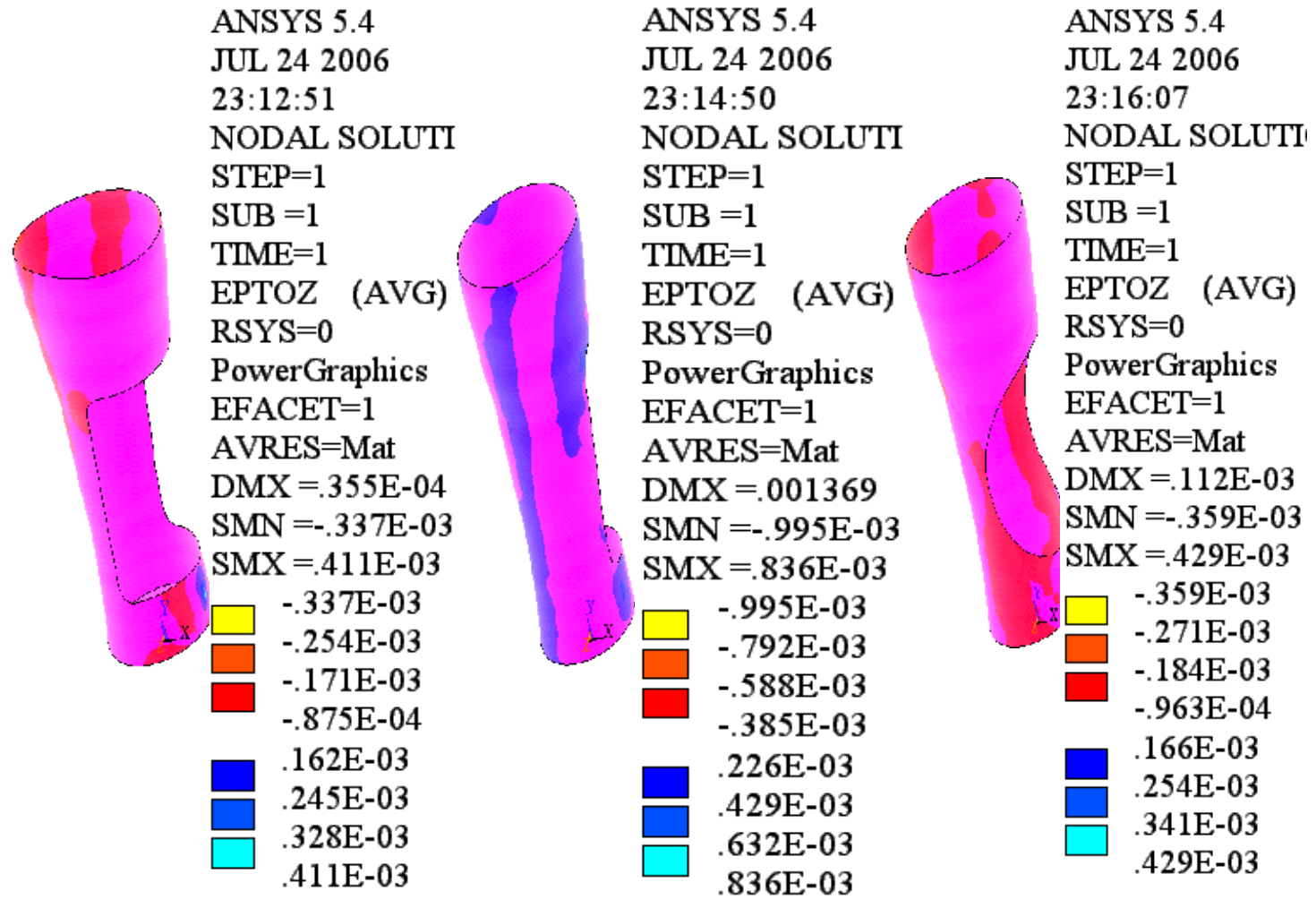

Figure (15) Contour lines of strain $\varepsilon_{\mathrm{z}}$ in the Syme socket models of $P S P, P S M$, and $P S P_{c i r}$ under loading at heel off.

\section{Conclusions:}

From this study the following two conclusions can be deducted: 
1.The sockets with posterior cut out are more convenience and have more strength than the others with medial cutout, the experimental and numerical results confirm.

2.Rectangular shape of socket opening is better than the circular shape and developing less stresses and strains.

\section{Refferences:}

1. Mclaurin, C.A., "The Syme prosthesis", In: Murdoch, G (ed.), Prosthetic and

Orthotic practice, Edward Arnold ub. (1970), pp.125-135.

2. Nanda, V., and Kumar, M.D., "Normal locomotion and prosthetic gait deviation", In: Williams \& Wilking (eds.), Rehabilitation management of amputees, Sikhar Nath Banerjee, (1982), pp. 237-254.

3. Peter Kohnke, "ANSYS theory reference, Release 5.4", Eight (ed.), ANSYS, Inc., Southpoint, (1997).

4. Engineering Materials Handbook, Vol.1, "Composites", ASM International Handbook Committee, Ohio, USA, 1985, pp. 223.

5. Hearn, E.J., " Mechanics of Materials", Pergamon Press Ltd., (1977), pp.350.

Rehalen, http \|rehalen.com, Website, Binningerstrasse, 